Portland State University

PDXScholar

\title{
A Comparison of the Cohesion in the Expository Discourse of the Optimally-Healthy Young-Old and the Optimally-Healthy Oldest-Old
}

Penni Gay Siemens

Portland State University

Follow this and additional works at: https://pdxscholar.library.pdx.edu/open_access_etds

Part of the Speech and Rhetorical Studies Commons

Let us know how access to this document benefits you.

\section{Recommended Citation}

Siemens, Penni Gay, "A Comparison of the Cohesion in the Expository Discourse of the Optimally-Healthy Young-Old and the Optimally-Healthy Oldest-Old" (1994). Dissertations and Theses. Paper 4781. https://doi.org/10.15760/etd.6665

This Thesis is brought to you for free and open access. It has been accepted for inclusion in Dissertations and Theses by an authorized administrator of PDXScholar. Please contact us if we can make this document more accessible: pdxscholar@pdx.edu. 


\section{THESIS APPROVAL}

The abstract and thesis of Penni Gay siemens for the Master of Science in speech Communication: Speech and Hearing Sciences were presented June 2, 1994, and accepted by the thesis committee and the department.

COMMITTEE APPROVALS:

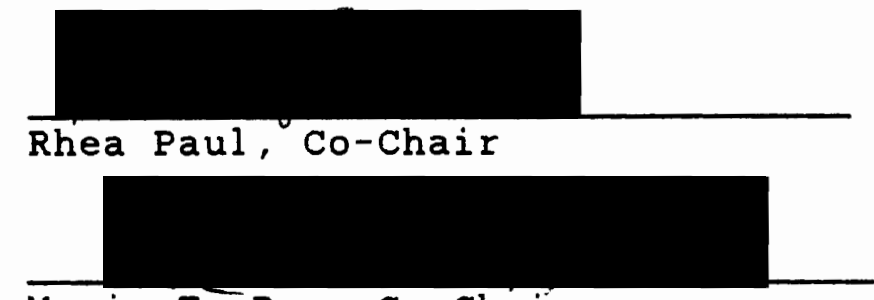

Marie T. Rau, Co-Chair

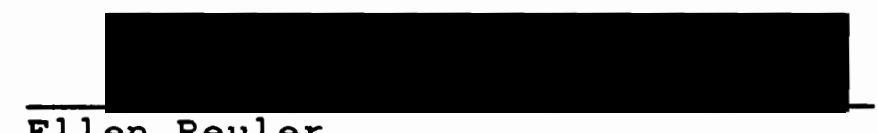

Ellen Reuler

DEPARTMENT APPROVAL:

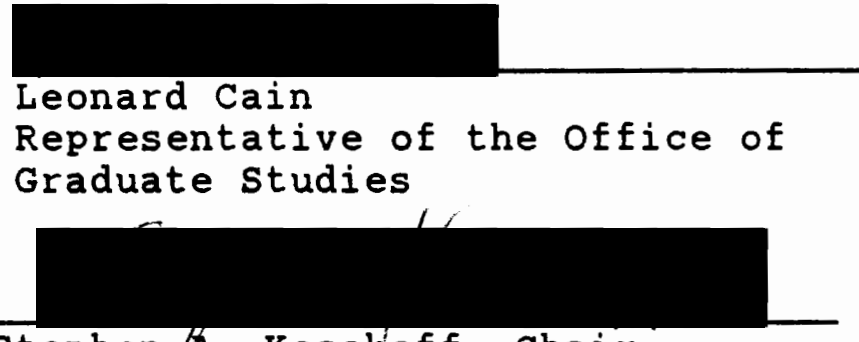

Stephen A. Kosokoff, Chair

Department of Speech Communication

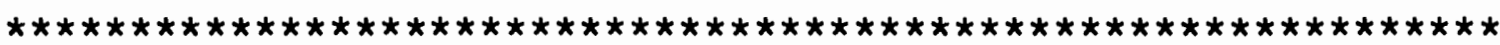

ACCEPTED FOR THE PORTLAND STATE UNIVERSITY LIBRARY

by

on

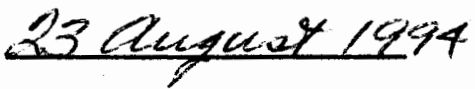




\begin{abstract}
An abstract of the thesis of Penni Gay siemens for the Master of Science in Speech Communication: Speech and Hearing science presented June 2, 1994.
\end{abstract}

Title: A Comparison of the Cohesion in the Expository Discourse of the Optimally-Healthy Young-old and the optimally-Healthy oldest-old.

The group of people aged 85 years and older is the fastest growing chronological population on the United States (Neal et al., 1993), and while a considerable amount of research has focused on the language of the elderly (those over 65 years), relatively little study has focused specifically on those aged 85 and older. This study is valuable in that it includes a large sample of optimallyhealthy people aged 85 and older. This sample of the optimally-healthy oldest-old will help define what changes, if any, are a function of age alone and what changes are clinical (associated with some disease, neurologic complication, or psychological impairment).

The purpose of this study was to compare two groups of elderly people's use of cohesion during an expository discourse task. This study also sought to answer the 
following question: If no health problems exist, does age alone affect the cohesion in the expository discourse of the elderly? To effect this comparison, a comparison of cohesive use in a group of 12 people between the ages of 65 and 75 years (the young-old) was contrasted with cohesion used by a group of 27 people aged 85 years and older (the oldest-old).

The subjects were gathered as part of the oregon Brain Aging study under the direction of doctors Diane Howieson and Jeffrey Kaye of the Portland VA Medical Center. The subjects had to meet strict inclusion and exclusion criteria. As part of the evaluations for the oregon Brain Aging Study, each subject was audiotaped while describing the fishing picture from the Neurobehavioral Cognitive Inventory (Kiernan et al., 1987). Each sample was then transcribed, divided into T-Units, and analyzed according to the cohesive analysis designed by Liles (1985) and Liles et al. (1989). Group comparisons for each aspect of cohesion (frequency, style, and adequacy) was completed using a $t$ test. No significant differences at the .05 level were found on any of the measures. 


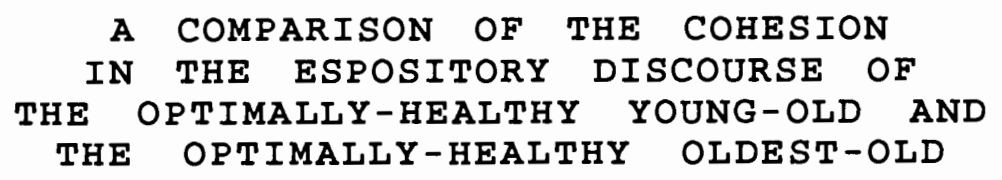

by

PENNI GAY SIEMENS

A thesis submitted in partial fulfillment of the requirements for the degree of

\author{
MASTER OF SCIENCE \\ in \\ SPEECH COMMUNICATION : \\ SPEECH AND HEARING SCIENCE
}

Portland state University

1994 


\section{DEDICATION}

This thesis is dedicated to the memory of Dad, my grandfather, Alvin C. Hinz. It was Dad's personality, perseverance, and lifestyle that made me question the "myths of aging" - he was (is) my inspiration. Dad has given me two of the greatest gifts I could ever receive - he showed me how to love life, and he showed me how to die. 


\section{ACKNOWLEDGMENTS}

I would like to acknowledge and thank many people who have provided guidance and support throughout this somewhat arduous process. I would like to thank my committee members for their assistance: Dr. Rhea Paul and Ellen Reuler of the Speech and Hearing Sciences program; Dr. Leonard Cain of the Sociology Department, and Dr. Judy Rau of the Portland Veteran's Administration Medical Center. Judy provided invaluable assistance and criticism while showing compassion and understanding. She made this project bearable. I would like to offer my sincerest gratitude to Dr. Robert Casteel, who fostered immense growth in me both professionally and personally.

I would also like to thank my friends and family. My parents have provided unfailing support throughout my college career and helped to instill the desire to meet my dreams. Alan, you made me dislike my situation enough to make a change, and you showed me a way to pattern my life to get the job done. And Greg - I can not thank you enough for your generosity of advice, friendship, and housing. I do not know how I would have made it through the graduate school experience without your being here - Thank you! 
TABLE OF CONTENTS

PAGE

PAGE

LIST OF TABLES ....................... vi CHAPTER

I INTRODUCTION $\ldots \ldots \ldots \ldots \ldots \ldots \ldots \ldots \ldots \ldots \ldots \ldots \ldots \ldots \ldots \ldots$

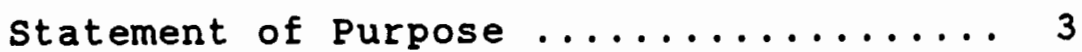

Definition of Terms ............... 4

I I REVIEW OF THE LITERATURE $\ldots \ldots \ldots \ldots \ldots$

Philosophies of Aging ............ 8

Common Perceptions of Aging

New Perceptions of Aging

Gathering Samples of Healthy

Elderly

Language and Aging

Discourse Analysis ................ 18

Gathering Discourse Samples

Cohesive Analysis

Sensitivity of Cohesive Analysis

Reliability of Cohesive Analysis

Cohesive Analysis and

Adult Language

Liles' (1985) Methodology ........... 26

Summary of Literature Review ........ 28

I I METHODS AND PROCEDURES $\ldots \ldots \ldots \ldots \ldots \ldots \ldots \ldots$

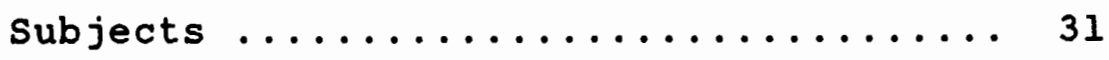

Subject Criteria

Description of Groups

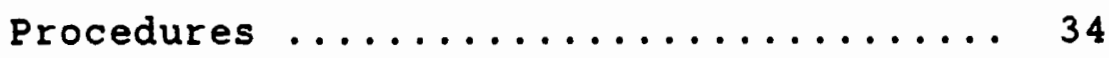




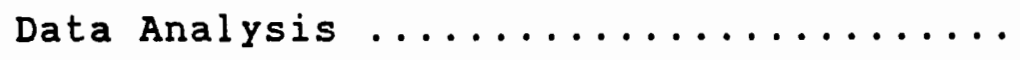

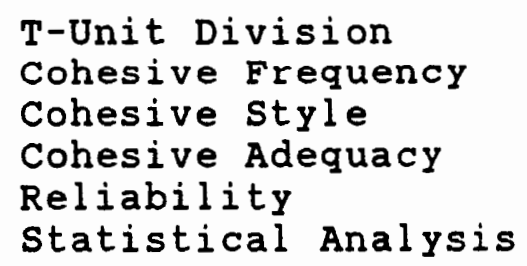

IV RESULTS AND DISCUSSION ............. 44

Results ..................... 44

Discussion ................. 47

V SUMMARY AND IMPLICATIONS $\ldots \ldots \ldots \ldots \ldots \ldots$

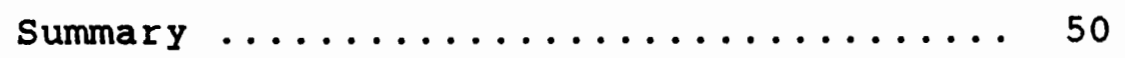

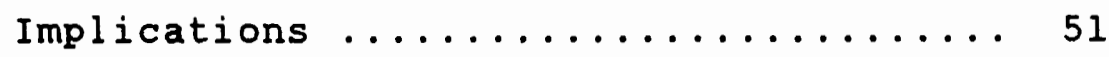

Research

Clinical

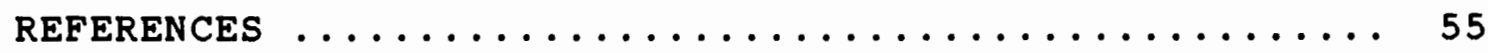

APPENDICES

A COHESION AND COHESIVE MARKERS .......... 60

B BATTERY OF NEUROLOGICAL AND NEUROLOGICAL

EXAMINATIONS OF HOWIESON ET AL. (1993)

AND KAYE ET AL. $(1994) \ldots \ldots \ldots \ldots \ldots \ldots \ldots \ldots \ldots$

C ADVERTisement SEEking VOLUNTEERS ......... 65

D FISHING PICTURE $\ldots \ldots \ldots \ldots \ldots \ldots \ldots \ldots \ldots$

E PROCEDURES FOR T-UNIT TRANSCRIPTION ....... 69

F PROCEDURES FOR COHESIVE ANALYSIS ........ 71

G SUMMARY OF SAMPLE SCORES ............ 78 


\section{LIST OF TABLES}

TABLE

PAGE

1 Subject Inclusion and Exclusion Criteria

2 Subject Profile of Kaye et al. (1992) and

Howieson et al. (1992) ............ 35

3 Subject Profile of Present study ........ 36

4 Descriptive statistics by Group and Dependent Variable .................... 44

$5 \quad t$-Values for Each Dependent Variable ..... 48 


\section{CHAPTER I}

\section{INTRODUCTION AND STATEMENT OF PURPOSE}

\section{Introduction}

The most rapidly expanding chronological age population in the United States is the one consisting of people aged 85 and older. While there is a considerable amount of research concerned with the elderly, relatively little study has focused specifically on those older than 85 (Neal, Pratt, \& Schafer, 1993; Rosenwaike 1985, as cited in Howieson, Holm, Kaye, Oken, \& Howieson, 1993). As this population grows, many questions come to mind. What, one might ask, can we expect of the cognitive function and communication skills of such a population? This study will compare one aspect of the communication skills of optimally healthy people aged 85 years and older (the oldest-old) with those of a similarly healthy group of young-old (ages 65-74).

It has only been in recent decades that a volume of work has concentrated on the effects of normal aging. Because people are living longer, the changes taking place across the life course are pertinent. In an attempt to describe the normal aging process, researchers have sought to determine if normal aging brings "inevitable decline" or if it is possible that there is "decrement with 
compensation" (Schaie \& Gribbin, 1975). The theory of inevitable decline proposes that as one ages, one will experience decreased capabilities across all domains with little hope of maintaining a self-sufficient lifestyle. In contrast, proponents of the decrement with compensation theory argue that decline is not an absolute - that aging is a developmental process. While some physiological processes, information processing, reaction time, and memory function have been shown to be affected by the aging process, there is also considerable data suggesting that, depending on their experiences, preconceptions of aging, and environment, people can inhibit or compensate for some of these changes (Hayslip, 1991).

Indeed, the declines presumed to be associated with aging are often found to be greatest in conjunction with some kind of disease, neurologic complication, or psychological impairment (Hayslip, 1991). How substantial would the declines of these processes be in the absence of such pathologies? This study seeks to answer this question by looking at potential changes in one aspect of verbal communication over the eighth and ninth decades of life. When examining adult language, many researchers have utilized some kind of discourse analysis. Discourse analysis provides extended, uninterrupted samples of the subject's language in a relatively natural context, therefore, offering insights into language beyond the word 
or sentence level. Since these are naturalistic samples, almost any aspect of language can be analyzed. Cohesive analysis, one type of discourse analysis, has often been used in studies involving adult language. Cohesive analysis examines the ways in which ideas are linked within a text. A text that has cohesion makes sense because the ideas are connected in a logical manner. This study utilized cohesive analysis to examine elderly adult language.

\section{Statement of Purpose}

The purpose of this study was to examine the cohesion in the discourse of older adults utilizing the method described by Liles (1985) and Liles, Coelho, Duffy, \& Zalagens (1989). Two groups of optimally healthy people were compared. The first group, the young-old, was between the ages of 65 and 75 years. The second group, the oldestold. consisted of people age 85 years and older. The span of ten years between the groups was imposed to clearly separate the young-old from the old-old. The study explored the following question: If no health problems exist, does age alone affect the cohesion of expository discourse in older adults? Three aspects of cohesion were examined: 1) cohesive frequency, 2) cohesive style, and 3) cohesive adequacy. Given that no pathologies are present and given that language seems to be a stable factor once learned, the following three null hypotheses were tested: 
1) There will be no significant difference, at the .05 level, in cohesive frequency in the expository discourse of the optimally healthy young-old and the optimally healthy oldest-old.

2) There will be no significant difference, at the .05 level, in cohesive style in the expository discourse of the optimally healthy young-old and the optimally healthy oldest-old.

3) There will be no significant difference, at the .05 level, in cohesive adequacy in the expository discourse of the optimally healthy young-old and the optimally healthy oldest-old.

\section{Definition of Terms}

For clarification and for easy reference, brief definitions of terms particular to this study are provided bel ow.

\section{General Terms}

1. Elderly or older adults - People 65 years of age and older

2. Younger adults - Unless otherwise stated, people between 18 and 64 years of age

3. Young-old - People between 65 and 75 years of age

4. oldest-old - People aged 85 and older

5. Decrement or Decline - A diminution of ability 
6. Compensation - In terms of "decrement with

compensation", compensation can be either a strategy used to dampen the effects of some decline or a skill that improves and/or continues to develop.

\section{Terms Associated with Discourse}

7. Discourse - "A unit of language which conveys a message" and is characterized by communicative function (Ulatowska \& Chapman, 1989, p. 299). There are four types of discourse:

A. Narrative discourse - Type of discourse used to tell a story. Its primary function is for entertainment.

B. Procedural discourse - Type of discourse used to give directions. Its primary function is to inform.

C. Communicative discourse - Type of discourse used during normal conversation.

D. Expository discourse - Type of discourse used to describe or discuss something. Its primary function is to describe/inform.

8. Text - The actual words, or linguistic factors, of discourse.

9. Context - The situation in which discourse takes place. Context incorporates "all those extra-linguistic factors ... affecting the linguistic choices being made" (Halliday \& Hasan, 1976, p. 21). Context includes the setting. participants, and the interactional rules associated with a given situation. 
Terms Associated with Cohesive Analysis

10. Cohesion - The semantic relationship between words, sentences, and larger aspects of a text. These relationships are built in such a way that one can identify the text as a connected whole rather than a jumble of unrelated words and ideas (Ulatowska \& Chapman, 1989). 11. Cohesive element or Cohesive marker - A word or implied information whose meaning can only be interpreted by information contained earlier in the text or within the context.

12. Referent - The information or item to which a cohesive marker refers.

13. Cohesive tie - The relationship between a cohesive marker and its referent. The nature of this relationship is characterized by the type of cohesive marker used. Five types of cohesive ties (markers) are commonly described (Halliday \& Hasan, 1976; Hedberg \& Stoel-Gammon, 1986;

Mentis \& Prutting, 1987). Appendix A provides examples of each type of cohesive marker and an explanation of the resulting cohesive tie.

A. Reference - The cohesive marker specifically refers to an item that can be directly retrieved within the text.

B. Substitution - The cohesive marker is substituted for the item to which it refers. When cohesive markers are used as substitutes, they are not used as an exact replacement for the referent. 
C. Ellipsis - The actual cohesive element is left unsaid, but rather is presupposed based on information given in the first half of the tie.

D. Conjunction - Involves the use of connective terms to link related parts of the text. These connective terms are commonly called conjunctions in English. The conjunction used will determine the exact nature of the cohesive relationship. For example, the conjunction "and" creates an additive relationship; whereas, the conjunction "but", suggests an adversative relationship.

E. Lexical - Cohesion is created because of the selected vocabulary. The cohesive element is somehow related to the referent, whether it be a direct repetition, a synonym, or a member of the same semantic class. 13. Cohesive frequency - The average number of cohesive markers appearing in each sentence of a text.

14. Cohesive style - The percentage of a particular type of cohesive marker occurring in a given text. Cohesive style is determined by dividing the frequency of each category of cohesive markers by the total number of cohesive markers appearing in the text.

15. Cohesive adequacy - A cohesive tie is considered complete if the referent can be easily identified. A cohesive tie is considered inadequate if the referent cannot be identified or if the cohesive marker is tied to an ambiguous referent. 
CHAPTER I I

REVIEW OF THE LITERATURE

The purpose of this literature review is twofold. The first section will concentrate on the aging process: what are common perceptions associated with aging, how do current researchers view the aging process, and what is known specifically about language in aging? The following section will review the use of discourse analysis, and particularly cohesive analysis, as a strategy to examine adult language. Concerning cohesion, the topics to be discussed include: (a) a description of cohesion and cohesive markers, (b) the ability of cohesive analysis to find a difference between groups if it exists, (c) the stability of cohesive analysis over time, (d) the results of studies that used cohesive analysis as a way to describe language in older adults, and (e) the effectiveness of Liles' (1985) methodology as a cohesive analysis strategy.

\section{Philosophies of Aging}

\section{Common perceptions of Aging}

Historically, the expectations of what aging brings have been rather bleak. Commonly held beliefs include the ideas that older people are less intelligent, are forgetful, 
are unable to grasp new ideas, are physically weak, and are emotionally fragile (Phillips \& Gaylord, 1985). In addition, as they age, people are thought to become less competent in self-care skills and in the ability to make appropriate choices in the tasks of daily living (Manney, 1975). One need only take a cursory look at the English language to find phrases that perpetuate these stereotypes. Phrases such as "old biddy", "dirty old man", and "old fool" do little to make the aging process more appealing (Manney, 1975). Certainly, it is undeniable that changes occur hair becomes grayer, faces become wrinkled. In addition, declines in visual and auditory acuity have been well documented (Howieson et al., 1993; Neal et al., (1993). The immune system weakens, muscles lose their tone, and organ systems become less adaptable to stress (Manney, 1975). Perhaps the areas of decline lending most credence to the negative stereotypes of aging are the psychological/cognitive changes. For instance, older people do indeed have slower responses, a decline in short-term memory, and diminished abilities in cognitive flexibility (Burke \& Light, 1981; Craik 1977; Hayslip, 1991; Schaie \& Hertzog, 1983).

\section{New Perceptions of Aging}

The theory of inevitable decline supports the dim views presented above; however, there is strong support for the notion that there is "decrement with compensation." 
Proponents of this theory posit that decline in aging is not an absolute; rather, aging is a developmental process. At each successive point in development, some opportunities (skills) open while others close (Manney, 1975). When speaking of compensation in this context, it can be defined either as a strategy used to dampen the effects of some deficit or as a skill that improves or continues to develop.

\section{Gathering Samples of Healthy Elderly}

When debating between "inevitable decline" and "decrement with compensation" it is important to control for variables that may exaggerate the effects of aging. North and Ulatowska (1981) found a strong correlation between overall competence in daily living skills (which is often related to overall health) and the quality of older adults' procedural and narrative discourse. High degrees of competence were also related to higher cognitive scores. Boult, Kane, Louis, Boult, \& McCaffrey (1994) suggest that chronic conditions (especially arthritis and cerebrovascular disease), educational level, and amount of social contact, all interacting with age, are variables that can predict future functional limitations. Of these variables, illhealth probably has the most significant effect and is also one of the more difficult factors to control. The difficulty lies in the simple fact that many elderly people exhibit signs of a chronic condition, such as hypertension 
(Neal et al., 1993), When health factors have been carefully controlled for, more confidence can be had in making inferences as to what effects age has on a person. For instance, Hultsch, Hammer, and Small (1993) found an inactive lifestyle and a poor self-report of health to be more predictive of declines in cognitive measures than chronological age. In a longitudinal study employing strict inclusion and exclusion criteria to ensure an optimally healthy sample, Howieson et al. (1993) found that "substantial cognitive decline is not inevitable in [healthy] persons in their ninth and tenth decades" (p. 1885). In a related study using the same subjects, Kaye, Oken, Howieson, Holm, \& Dennison (1994) found similar results.

\section{Language and Aging}

Despite interest in the aging process, normative information about language in the healthy elderly (those older than 65), and particularly the healthy oldest-old (people aged 85 and older), is comparatively slim.

Information about language in adults, at any age, has largely been gathered as a control in an attempt to describe the language of people with various communication-related pathologies. That is, research questions for such studies focused on the communication of closed-head-injured-adults (Liles et al., 1989; Mentis \& Prutting 1987), people with aphasia (Bottenberg \& Lemme, 1991; Ulatowska, Freedman- 
Stern, Weiss-Doyel, \& Macaluso-Haynes, 1983), or people with Alzheimer's Disease (Cherney \& Canter, 1991; Smith, Murdoch, \& Cherney, 1989; Warren, Bayles, \& Trosset, 1991). Although some research has focused on the language of neurologically normal adults, much of it has been primarily concerned with adult language in general, not specifically the language of the elderly. Furthermore, research studies involving the healthy elderly often have not imposed a strict definition of healthy and only rarely have divided the elderly into two groups: the young-old and the oldest-old (Howieson et al., 1993; Kaye et al., 1994).

Although historically it has been assumed that language abilities remain fairly constant once established, when reviewing what is known about language and aging, it appears that declines in some receptive and expressive abilities may occur, but that there may be improvements in related linguistic skills. Several early studies investigating expressive language form support the historical notion by suggesting that lexical organization, grammar, and syntax remain stable across the life course (Botwinick, West, \& Storandt, 1975; Lovelace \& Cooley, 1982; Riegel, 1968). Much of the more recent research, however, has been more concerned with receptive language abilities and how these are related to other higher-level cognitive functions. To examine these relationships, some kind of text recall task has often been utilized. In these tasks, the subjects 
either listen to or read a prose passage and then are asked to recall specific information. Text recall has been used to assess the ability to comprehend new information, the depth of semantic processing, and the ability to make inferences from this new knowledge. In general, the results of these studies show a general slowing of response time and a diminution in delayed text-recall: answering specific questions and making accurate inferences about the text after it has been removed from reference and/or after a period of time. Despite these decrements, the results of text-recall studies have also generally found no decrease in immediate text-recall abilities. The following section reviews the somewhat opposing results of studies using this text-recall tasks.

Belmore (198I) observed older people's ability to comprehend short passages, make inferences about them, and to retain this information. Older adults ( $58-74$ years), although taking more time, accurately responded to test stimuli as well as the younger adults; however, when asked to recall the same information a week later, the older adults were significantly less accurate. Belmore concluded that comprehension is evidently not affected by age, but that long-term memory of new information may be adversely affected.

Light, Zelinski, and Moore (1982) found that older adults aged 50-82 had poorer fact memory and were less 
confident of their accuracy than younger, college-aged students. Lack of confidence was observed to correlate closely with low inference scores for both young and old; however, the groups were similar in their ability to make inferences about a text when able to refer back to it. older adults did show a significant decline in making inferences on a delayed task. The differences were exaggerated when the new information was presented in a confusing manner. Light and her colleagues proposed that their results indicate a general decline in processing speed. This, in turn, places a burden on working-memory: the ability to process information, keep it available for reference, and to make judgements based on that information. Simon, Dixon, Nowack, \& Hultsch (1982) observed how depth of processing interacted with intentional and incidental text recall of young ( $18-32$ years), middle-aged (39-51 years) and older (59-76 years) adults. Simon and his colleagues worked under the theoretical assumption that depth of text processing would be influenced by the way the subjects were asked to manipulate a prose passage. Each age group was subdivided into four test groups. Three groups were given incidental recall tasks requiring progressively deeper semantic processing. One group analyzed grammar and syntax, another group rated the quality of the passage, and yet another group wrote "advice" to the main characters in the passage. The fourth group was told to read and remember 
the story. This task examined intentional recall of text details. All four groups were asked to answer specific questions about the story. None of the age groups differed on either the intentional recall task or the incidental recall task following the most shallow processing procedure. The incidental recall of the middle-aged group older group after the two deeper processing tasks were significantly worse than that of the younger group. Although each age group successfully and similarly completed each of the orienting tasks, the depth of semantic processing required tended not to help the older adults in incidental recall of the story. These results suggest that older adults are able to comprehend a text, evaluate it, and make inferences from it, but once the text is removed from sight, they are less able to remember specific details about it unless specifically instructed.

Meyer and Rice (1981) found no difference in the abilities of older adults and young adults to remember and interpret main ideas about a text; however, the younger group recalled fewer subordinate details. Meyer and Rice suggest that the younger adults, who were college students, were used to reading to get the major ideas of a text, but older adults could afford to be more casual and focus on incidental items of interest as well. These results are roughly commensurate with those found earlier by Meyer et al. (1979, as cited in Meyer \& Rice 1981); Dixon, Simon, 
Nowack, \& Hultsch (1982), and Taub (1975). Meyer and Rice (1981) propose that the heterogeneity of education, lifestyle, and other "cultural[ly] related generational differences" (p. 254) among the elderly help to explain the apparently conflicting results of other studies (e.g.. Cohen, 1979).

North, Ulatowska, Macaluso-Haynes, \& Bell (1986) added a task of communicative competence to their investigation of text recall. They compared the language of a group of well educated younger women with that of a group of similarly educated older women. Each subject was given a narrative discourse task, a procedural discourse task, a structured interview, and two nonverbal cognitive tests. The older subjects performed more poorly on the cognitive tests, recalled fewer details on the discourse tasks, and were rated as less communicatively competent during the interview. The structured interview was conducted to assess cognitive functioning. As such, a more formal interchange was expected. North and his colleague suggested that the older group performed poorly during the interview because they mistakenly interpreted the interview as a casual conversation. In fact, the researchers pointed out that several of the older subjects changed their communicative style upon realizing the purpose of the interview. This is an indication that the ability to code-switch (to change communication style according to the situation) is not 
necessarily affected by age. It is also important to note that in the older group, communicative competence was correlated with scores on the cognitive tests. Since the subjects were not controlled for health status, perhaps the disparity was due to health-related factors as opposed to age.

Studies focusing primarily on expressive language, especially discourse, have shown strong support for the idea of decrement with compensation. Ulatowska, Cannito, Hayashi, and Fleming (1985) investigated both the structure and use of pronouns in the discourse of a group of young-old and a group of people older than 76. Although the older group showed less adequate use of pronouns, their discourse structure remained intact, and in some cases, was more elaborate. The idea of decrement with compensation is further advanced by obler (1980), who found the written discourse of adults between the ages of 30 and 39 and adults older than 70 to be more elaborate than that of healthy adults between the ages of 30 and 69 . Kemper (1990) also found the written discourse of adults to become more detailed as they aged; however, the discourse became less cohesively adequate. Moreover, Pratt and Robins (1991) found that the personal narratives of older adults (60-87) were judged by the untrained listener to be superior to those of younger adults (18-55). 
Discourse Analysis

Many of the previously mentioned studies have incorporated some kind of discourse analysis. The strength of this analysis lies in the fact that the sample is gathered in a real communicative context, meaning there is a purpose to the task. Given that, the sample provides not only a good example of a subject's language structure and form, but also of the subject's communicative competence. To create a clearer understanding of the benefits of using discourse analysis, a more complete description must be given. There are many explanations available; however, most are based on the paradigm proposed by Halliday and Hasan (1976, 1986). They offer the text, discourse, as a socialsemiotic. That is, any verbal communication (whether spoken or written) has a social context and serves the purpose of building verbal signs to create meaning. The four basic types of discourse (narrative, procedural, conversational, and expository) are each related to a specific communication function (Halliday \& Hasan, 1976; Hedberg \& Stoel-Gammon, 1986; Shadden, Burnette, Eikenberry, \& DiBrezo, 1991; Ulatowska \& Chapman, 1989).

\section{Gathering Discourse Samples}

Ulatowska and Chapman (1989) explained that "the distinct structural organization and content of each 
discourse type [places] different cognitive and linguistic demands on the communicator" (p. 299); therefore, the samples elicited by each type of discourse can be quite different. Simply put, the discourse structure and the words the speaker chooses to use will be affected by the communicative situation, or context. Given this, and given that discourse samples have become widely used in describing childhood and adult language, there has been increasing debate about which type of discourse task and which style of stimulus produce the richest samples.

The length of the discourse sample appears to be related to the type of discourse task. Bottenberg, Lemme, and Hedberg (1987) and shadden et al. (1991) found that narrative discourse tasks tended to produce longer samples than did either procedural or expository discourse tasks. The length of discourse sample, however, is not the only concern. The guality of the sample is also important. When comparing the quality of the samples elicited by different types of discourse, Bottenberg and her colleagues (1987) found fewer occurrences of cohesive ties in the expository task than in either the narrative or procedural task; in contrast, no significant differences in number of ties were found in the shadden et al. (1991) study. Furthermore, Bottenberg and her colleagues (1987) found no significant differences in the number of failed attempts at making cohesive ties, but when errors did occur, they 
appeared most often in the expository context. The disparity in the results may stem from the fact that the Bottenberg (1987) study compared a group of aphasic patients older than 65 years with a control group; whereas, shadden et al. (1991) observed the discourse abilities of healthy women between the ages of 60 and 85 . It therefore appears that expository texts tend to be shorter and may have fewer instances of cohesive ties, but they may also be a good measure in distinguishing the differences in the cohesive abilities of two sample groups.

Given the communicative differences between the types of discourse tasks, it is not surprising that some types tend to elicit longer samples and different language structure. Another factor that may come into play is the kind of stimulus used to collect the sample. An expository task is often elicited by asking the subject to describe a black and white picture; whereas, narratives are often elicited using a sequence of pictures, giving many more contextual clues from which to work (Bond et al., 2983; Bottenberg et al., 1985; Lemme, Hedberg, \& stoel-Gammon, 1984; all cited in Bottenberg et al., 1987). When eliciting discourse samples, one must be aware of the type of discourse being recorded before making any judgments on its length and communicative adequacy. Being aware of the contextual limitations of each type of discourse, however, one should be able to obtain, at the very least, enough 
information to adequately compare the language functioning of different groups in a given situation.

\section{Cohesive Analysis}

Cohesive analysis, one of many ways used to examine adult discourse samples, provides particular insight into the semantic skills of the subject. Halliday and Hasan (1976, 1986) said that it is cohesion that characterizes a text. Mentis and Prutting (1987) described cohesion as being a "semantic relation by which the interpretation of one element in a text can only be made by reference to another" (p. 88). In other words, cohesion is what makes a particular text make sense - the individual parts of a text are logically linked to make a coherent, understandable whole. Coherence is achieved when the images and ideas of a text are linked together through the use of cohesive markers, or cohesive elements. These markers are words (or implied information) in one sentence whose meaning can not be fully understood and/or interpreted without knowledge of information that has been previously given (Halliday \& Hasan 1976). This prior information either can be found within the actual text or can be inferred because of the context in which the text occurs (exophoric reference). The relationship between a cohesive marker and the information to which it is linked (its referent) is called a cohesive tie. The "tying" of these two elements creates "meaningful interdependencies" among the words (Mentis \& Prutting, 
1987). The nature of the relationship between the cohesive marker and its referent is characterized by the type of marker used. A brief definition of each type of marker is found in the definition of terms, and illustrations of the semantic relationship created by each tie are provided in Appendix A.

Sensitivity of Cohesive Analysis. As there are many ways to analyze a text, the question arises whether cohesive analysis is sensitive enough to find differences, if they exist, between two sample groups. Bottenberg and Lemme (1991) compared the cohesion in the discourse of normal and of aphasic adults in two different communicative contexts. During one task, the subject operated within a shared knowledge context where the subject and the examiner were viewing an illustration at the same time. In the other context, knowledge of the stimulus was unshared - the subject was the only one to view the pictures. There were 14 subjects in the control group, which had a mean age of 50 years. Ten independent variables were tracked, including cohesive frequency, type, and adequacy. For both groups, the frequency of cohesive elements, the types of cohesion, and the adequacy of cohesion did not differ across communicative contexts. However, the two groups differed in cohesive type and cohesive adequacy. Subjects in the experimental group used more lexical cohesive markers and produced less adequate cohesive ties. These results are 
important in two regards. First, these findings lend support to the idea that cohesive analysis is sensitive enough to find a difference between groups. Secondly, although Bottenberg and Lemme questioned the strength of the unshared knowledge task, these results indicate that the type and frequency of cohesive elements and the adequacy of their resultant cohesive ties are fairly constant across contexts, regardless of whether the listener is already knowledgeable about the content. Other studies have used cohesive analysis to distinguish successfully between neurologically impaired populations and neurologically normal populations (Cherney \& Canter, 1990; Mentis \& Prutting, 1987; Smith, Murdoch, \& Cherney, 1989; Warren, Bayles, \& Trossett, 1991).

Reliability of Cohesive Analysis. The ability of cohesive analysis to find differences has little significance if the measure is not reliable. Studies utilizing cohesive analysis have found strong point-to-point reliability between judges. In a study comparing the cohesion in the discourse of people with closed-headinjuries and a control group, Mentis and Prutting (1987) obtained inter-judge reliability measures ranging between 808 and 1008, with measures for the reference category being the least reliable and measures for incomplete ties being the most reliable. Cherney and Canter (1990) reached 948 agreement on coding pronouns without adequate referents. 
Cohesive analysis has been shown to be quite reliable when considering the ability of two or more judges to similarly rate a given discourse sample, but strong and Shaver (1991) questioned the ability of cohesive analysis to obtain reliable scores in the discourse of children over a two week period of time. Narratives of 39 non-language disordered children and 39 language disordered children were recorded three times over a two week period. strong and Shaver used an analysis containing the components of Liles' (1985) procedure: cohesive frequency, cohesive style, and cohesive adequacy. Test-retest reliability measures were strong in terms of cohesive frequency, cohesive style, and cohesive adequacy when distinguishing differences between and within groups across a period of time. However, the measures were less reliable in describing any individual's use of cohesion over time. These results suggest that when concerned primarily with distinguishing differences between sample groups, cohesive analysis is a repeatable measure; however, when desiring information about an individual's discourse over time, it is less reliable.

Cohesive Analysis and Adult Language. Cohesive analysis has been shown to be both a sensitive and reliable measure, but what have results of studies using cohesive analysis revealed about elderly language?

Ulatowska and Chapman (1989) compared the discourse of two neurologically impaired populations with the performance 
of two control groups: a group of neurologically normal young-old and a group of neurologically normal oldest-old. Among other differences, they found significantly more errors of indefinite and inadequate reference among the oldest-old compared to the young-old.

similar results were found in a study examining the written narratives of older adults (Kemper, 1990). Wishing to document age changes in cohesion and story structure, Kemper analyzed longitudinal diary samples of 8 adults in their eighties and nineties. A total of seven samples were taken from each subject's diary, with the passages representing every decade of the subject's adulthood (aged 20 and older). As they aged, the subjects tended to use a more complex story structure, incorporating conflict, resolution, and character motivations. Despite the increasing complexity of story structure, the narratives showed a general decline in cohesive adequacy. In fact, the high school English teachers who graded every sample, judged entries written during the subjects' $70^{\prime} \mathrm{s}$ and $80^{\prime} \mathrm{s}$ to be both more interesting and technically better than the earlier ones, regardless of the general decline in cohesive adequacy. Since complex narrative structure is dependent on higher level language skills (Roth \& Spekman, 1989), these results suggest that if there is a cognitive decline in old age, it does not uniformly affect all higher level functions. Just as important, these results lend credence 
to the decrement with compensation theory - cohesive ability declines (a decrement) as story structure becomes more complex (a compensation). Furthermore, these results and those of Ulatowska and Chapman (1989) suggest that cohesive ability is affected by age and may be an area that could differentiate between a sample of young-old and old-old.

\section{Liles' (1985) Methodology}

Many methods of cohesive analysis have been devised. In their cohesive analyses, Halliday and Hasan (1976) observed cohesion in any text, whether it be a novel or everyday communication. In doing so, they were primarily interested in cohesive type. In the field of speechlanguage pathology where deviant and disordered language is studied, many researchers have included cohesive adequacy in their investigations (Kemper, 1990; Mentis \& Prutting, 1987). Cohesive adequacy is usually determined by an evaluation of whether the presence of a cohesive marker clearly refers back to prior information or if its presence leads to misleading information (Liles 1985) and Liles et al. (1989). Adapting Halliday's and Hasan's analysis (1976), Liles (1985) observed the cohesion in the discourse of school-aged children utilizing all three aspects of cohesion: cohesive type, cohesive frequency, and cohesive adequacy. More specifically, Liles determined what types of cohesive markers were used, how often each type occurred, 
and how effective each tie was.

Liles originally developed her analysis to compare the cohesion in the narratives of language disordered and nonlanguage disordered children. In this study, both interexaminer and intra-examiner reliability for the analysis were greater than $94 \%$. Results suggested a significant difference in the cohesive abilities of the two subject groups. Although Liles developed this analysis to describe the differences between the narratives of normal and language disordered children, she has since used it to analyze the narratives of normal adults, closed-head injured adults, and aphasic adults.

Liles et al. (1989) compared 4 closed head injured adults with 23 young adults in a story retelling and a story generation task. In the retelling task, the subjects were asked to repeat a story that they heard in a filmstrip. In the story generation task, they were asked to tell a story about a Norman Rockwell picture. Both groups produced longer and more detailed narratives on the retelling task, and they did not qualitatively differ in their performances. On the story generation task, however, there was a significant difference between the groups in terms of cohesive style, cohesive adequacy, and story grammar. These findings suggest that Liles' method of cohesive analysis is sensitive to the differences between pathologic and normal language. Additionally, these results suggest that 
differences between groups may be more apparent when the subjects have to generate the text.

\section{Summary of Literature Review}

In reviewing what is known about the effect of aging on language and discourse skills, several themes need reiterating. While there is a considerable volume of research concerned with the normal aging process, most studies including a group composed exclusively of healthy people older than 85 have not imposed as strict inclusion and exclusion criteria as did Howieson et al. (1993) and Kaye et al. (1994) when attempting to isolate age as the sole independent variable. Decrements in some physiological and perhaps some psychological processes are unavoidable aspects of aging; however, these declines (particularly in the psychological processes) often appear in conjunction with some kind of compensatory skill. The idea of decrement with compensation is supported by the results of several studies investigating language and discourse in older adults. While there appear to be declines in language processing and some linguistic skills (Kynette \& Kemper, 1986; North et al., 1986; Ulatowska et al., 1985), some discourse skills, such as the complexity of story structure, appear to increase with age (e.g., Kemper, 1990). When examining the language abilities of the elderly, discourse analysis is most effective in that it offers extended 
samples and allows analysis beyond the word and sentence level (Cannito, Hayashi, \& Ulatowska, 1988). Furthermore, cohesive analyses, in particular Liles' (1985) method, have been found to be both sensitive to and reliable in finding differences, if they exist, among varying populations. 


\section{METHODS AND PROCEDURES}

The expository discourse samples analyzed in this study were taken from a previously established data base collected by Howieson, Kaye, and Howieson (1990) as part of the ongoing longitudinal oregon Brain Aging study. It should be noted that the subject selection and methods of data collection for this study were performed by Howieson et al. (1990), while the data analyses and subsequent statistical analyses were decided upon by this researcher. As part of the Oregon Brain Aging Study, Howieson et al. (1993) and Kaye et al. (1994) administered a wide battery of evaluations to compare the neurological and neuropsychological functioning of the young-old and the oldest-old. This battery included an examination of the primary sensory and motor systems along with several portions of the Wechsler Adult Intelligence Test - Revised (Wechsler, 1988, as cited in Howieson et al., 1993) and the Wechsler Memory Scales - Revised (Wechsler, 1987, as cited in Howieson et al., 1993). A list of the complete battery is shown in Appendix B. As Howieson, Kaye, and their colleagues wished to isolate age as a variable, they established strict inclusion and exclusion criteria in an 
effort to obtain an optimally healthy sample.

$$
\text { Subjects }
$$

The subjects were originally selected from functionally independent volunteers recruited from retirement homes, senior organizations, and advertising about the project (see Appendix $C$ for sample advertisement).

\section{Subject Criteria}

Each volunteer had to pass stringent health screening criteria before being included in the sample. A complete description of these criteria are shown in Table l; however, some highlights are provided below. To be included in the sample, volunteers had to be functionaliy independent as determined by a score greater than or equal to 12 on the Instrumental Activities of Daily Living Scale from the OARS (Fillenbaum \& Smyer, 1981, as cited in Howieson et al., 1993). Volunteers were excluded if they showed signs of a past or present neurological illness, a medical condition that could alter brain functioning, or vascular disease. volunteers were also excluded if they exhibited symptoms of depression as measured by a score greater than 10 on the Geriatric Depression Scale (Koenig, Meador, Cohen, \& Blazer, 1988; Yesavage, Brink, Rose, \& Lum, 1983; both as cited in Howieson et al., 1993) or a score greater than 11 on the Cornell Depression Scale (Alexopoulos, Abrams, Young, \& Shamoian, 1988, as cited in Howieson et al., 1993). 
Table 1

Subject Inclusion and Exclusion Criteria for Howiwson et al. (1993) and Kaye et al. (1994)

Inclusion

Exclusion

1. Functionally indepedent

1. Diabetes

2. English as primary language

2. Hypertension

3. Read (with glasses) $4 \mathrm{~mm}$ print

3. Angina

4. Hear (with aids) normal

4. Cardiac arrhytmia conversation

5. Pulmonary disease

5. Score 0 on Clinical Dementia Scale

6. Cancer

6. Score $\geq 24$ on the Mini-Mental

7. Transient ischemic State Examination attacks

7. Score $\leq 10$ on Cornell

8. Stroke Depression Scale

9. Head injury / loss of

8. Score $\leq 11$ on Geriatric consciousness > $5 \mathrm{~min}$. Depression Scale

10. Neurologic disease

11. Cardiac or coronary surgery

12. Drug or alcohol abuse

13. Past evaluation for cognitive or behavioral impaiment

14. On medication

Note: Medical records were checked to verify medical histories 
Furthermore, subjects were excluded if they had recently undergone major surgery or were currently on medication which could affect cognitive functioning. Volunteers were initially screened via a telephone interview. Upon completing this, they were mailed a medical history questionnaire. This was followed by a neurological evaluation, which was in turn followed ( 1 to 2 weeks later) by a neuropsychological evaluation and an MRI scan. The difficulty of gathering such a large sample of optimally healthy elderly is apparent when considering the number of potential subjects who were excluded from the sample. Of the first 250 people expressing interest in participating, only 1 out of every 17 people met the inclusion criteria. These potential subjects were most often rejected because they were too young or exhibited a history of hypertension. Of the 55 people accepted for the studies, only 4 subjects were rejected after completing the physical and mental health evaluations: one subject exhibited signs of depression, two subjects had an abnormal MRI, and another subject was reluctant to sign the consent form.

\section{Description of Groups}

For the original studies conducted by Howieson et al. (1993) and Kaye et al. (1994), there were a total of 51 subjects. The older group had 34 subjects with a mean age of 88.8 years (range $=84-100$ ), while the younger group had 
17 subjects with a mean age of 69.9 (range $=65-74$ ). Twotailed $\underline{t}$-tests showed that these groups did not significantly differ in terms of female to male ratio, educational level, socio-economic status, vocabulary, or scores on the Geriatric Depression Scale and the Cornell Depression scale. All subjects were Caucasian. Subject characteristics for Howieson et al. (1993) and Kaye et al. (1994) are summarized in Table 2 .

During the original battery of testing, Howieson et al. (1993) and Kaye et al. (1994) collected a language sample from 39 of the subjects. These samples are the basis for the present study. Of the 39 subjects, 27 are from the oldest group (mean age $=90$, range $=84-101$ ), and 12 are from the younger group (mean age $=70.4$, range $=66-75$ ). Two-tailed t-tests revealed that these groups did not significantly differ in terms of female to male ratio and mean educational level. Subject characteristics for this study are displayed in Table 3 .

\section{Procedures}

The data collection took place in a quiet clinic room. subjects were asked to tell everything they could about the "fishing picture" from the Neurobehavioral Cognitive status Exam as shown in Appendix D (Kiernan et al., 1987). The examiner asked each subject to describe the picture. He answered any questions posed to him, but he did not give 
Table 2

Subject Characteristic Profile of Howieson et al. 11993 and Kaye et al. (1994)

\section{Groups}

Characteristic

Young-Old

17

Number

Mean Age

\% Women

Mean Educational

Level

14 yrs.
Oldest-old

$p$

34

70.3 yrs.

89.0 yrs.

538

0.62

14 yrs.

0.87 
Table 3

Subiect Characteristics of Present study

\begin{tabular}{lccc} 
& \multicolumn{3}{c}{ Groups } \\
\cline { 2 - 4 } Characteristic & Young-old & Oldest-old & t-value \\
\hline Number & 12 & 27 & - \\
Mean Age & 70 yrs. & 89.9 yrs. & - \\
\& Women & 338 & 638 & 1.74 \\
Mean Educational & 13.5 yrs & 14.5 yrs & .84 \\
Level & & & \\
\hline
\end{tabular}


prompts within the description (i.e., "What happened next?"). Each sample was recorded on audiotape, with the date and subject's name being the only identifying information. The subjects' ages were not known by the judges of the present study until after analysis to control for any scoring bias that might have occurred.

Data Analysis

The samples were independently transcribed directly from the audiotapes by this investigator and another graduate student. Upon transcription, each sample was divided into $\mathrm{T}$-Units and analyzed according to the procedures set forth by Liles (1985). Three measures of cohesion (cohesive frequency, cohesive style, and cohesive adequacy) were calculated for each sample.

\section{T-Unit Division}

The samples were divided into T-Units so that a uniform way of distinguishing utterance boundaries could be established. A T-Unit can be viewed in a general sense as a main clause and those elements relating to it. A T-Unit, as defined by scott $(1988$, p. 55), is:

A main clause with all subordinate clauses or nonclausal structures attached to or embedded within. All main clauses that begin with coordinating conjunctions AND, BUT, OR initiate a new T-Unit unless there is a co-referential subject deletion in the second clause.

The guidelines for T-Unit transcription developed by strong 
and Shaver (1991) were also followed in this study and are shown in Appendix $E$.

\section{Cohesive Erequency}

Cohesive frequency is a measure of the average number of cohesive markers per T-Unit. To determine cohesive frequency, a rater read each sample and circled each cohesive marker. The measurement of cohesive frequency was obtained by dividing the total number of cohesive markers by the total number of T-Units.

\section{Cohesive style}

Cohesive style was determined by the percentage of cohesive markers in each sample that were either reference, conjunction, lexical, elliptical, or substitution, respectively. To rate cohesive style, a judge referred to all the markers identified when determining cohesive Erequency. They then recorded each marker on a score sheet, noted the type of marker it was, and specified in which T-unit it occurred. As an example, the cohesive markers are identified and classified in the following excerpt:

1. The girl is sleeping

2. And she's been fishing

3. There's a fish on her hook

4. But it hasn't awakened her In T-Unit 2, the words "and" and "she" are considered 
cohesive markers - "and" is a marker of conjunction; whereas, "she" is a marker of reference. Likewise in T-Unit 3, "her" is a marker of reference and "hook" is a lexical marker relating back to fishing. Finally, the cohesive markers in T-Unit 4 are "but", a conjunctive marker, "it", a referential marker, "awakened", a lexical marker, and "her", another referential marker.

Liles (1985) codes only markers indicating reference, conjunction, and lexical relationships because these have been found to be the most reliable measures. While all five were coded in this study, only the three used in Liles' (1985) methodology were included in the statistical analyses.

\section{Cohesive Adequacy}

The adequacy of the cohesive ties was described in terms of being complete, or incomplete and/or inadequate. A tie was considered complete if the information to which a cohesive marker referred could be defined without ambiguity. The following are examples of two complete ties:

1. Well there's a lady out there sitting on the lawn

2. And she's got a fishing pole In the second T-Unit, "and" clearly defines the additive relationship between the two T-Units, and "she" obviously refers to the lady in the first $T$-Unit.

The tie was incomplete/inadequate if the referent was either unclear or not present. Examples of incomplete 
ties include:

1. The picture is a boy that went fishing and went to sleep at the same time

2. They have another boy driving along beside them that's astonished at the view

The words "they" and "them" in T-Unit 2 appear to refer to the boy in the first T-Unit; however since these are plural pronouns and the apparent referent is singular, their usage leads to ambiguous information.

Cohesive adequacy was coded on the same score sheet used to code cohesive style. For each marker listed, a judge found the item in the text (if one was there) to which it referred. They then made a decision as to the adequacy of the tie. The percentage of adequate ties to the total number of cohesive markers was obtained. A completed scored sample and score sheet are provided in Appendix F.

\section{Reliability}

Each of the samples was independently transcribed verbatim by two judges for reliability purposes. The few disagreements were resolved by a second listening of the samples with both examiners present. Three disagreements still occurred, and an unbiased third listener made the final decision on these.

A measure of inter-rater reliability for T-unit unit transcription was calculated for approximately $10 \%$ of the samples. The point-to-point reliability, dividing the total 
number of $\mathrm{T}$-Units in agreement by the total number of T-Units in agreement and disagreement, was approximately 928.

Measures of inter-rater reliability and intra-rater reliability were calculated for each measure of cohesion. Approximately $20 \%$ of the samples were scored for cohesive Erequency, cohesive style, and cohesive adequacy by a certified speech-language pathologist trained in the procedures. Point-to-point comparisons yielded approximately $80 \%$ agreement on cohesive frequency (dividing the total number of cohesive markers identified in agreement by the total number of cohesive markers identified in agreement and disagreement). For the measures of cohesive style and cohesive adequacy, only the markers identified by both judges as being cohesive markers were included in inter-rater reliability computations. For cohesive style, point-to-point comparisons were computed by dividing the total number of markers of a particular type identified by both judges by the total number of agreements and disagreements for that type; therefore, every disagreement within each cohesive category was counted. For instance, reliability for markers of reference was determined by dividing the total number of markers identified by both judges as being referential by the total number of markers identified as being referential by either judge. If one judge recorded a marker as referential but the other judge 
recorded the same marker as being lexical, the disagreement would be counted in both the referential and lexical interrater reliability calculations. Inter-rater reliability scores for cohesive style include: (a) 938 agreement on markers of reference, (b) $100 \%$ agreement on markers of conjunction, (c) $80 \%$ agreement on lexical markers, (d) $0 \%$ agreement on markers of substitution and, (e) $0 \%$ agreement on elliptical markers. The $0 \%$ agreement on markers of substitution and ellipsis are commensurate with inter-rater reliability scores found by Liles (1985) and Liles et al. (1989) for these measures. The inter-rater reliability score was $100 \%$ for identification of cohesive adequacy (dividing the total number of complete and incomplete judgements in agreement by the total number of complete and incomplete judgements in agreement and disagreement).

Intra-rater reliability was determined on approximately $10 \%$ of the samples using the procedures described above. The results of these comparisons were: (a) $88 \%$ agreement for cohesive Erequency, (b) $100 \%$ agreement for markers of reference, (c) $100 \%$ agreement for markers of conjunction, (d) 1008 agreement for lexical markers, (e) 668 for markers of substitution, (f) $100 \%$ agreement for elliptical markers, and (g) $100 \%$ agreement for cohesive adequacy.

\section{Statistical Analysis}

Statistical analyses were completed separately for each variable. Kaye et al. (1994) employed both parametric 
and nonparametric statistics when analyzing the results of the neurological evaluations and found the two methods to yield identical results. In light of this, parametric statistics were used in the present study. Means, variances, and standard deviations were determined within each age group for cohesive frequency, three types of cohesive markers, and percentage of adequate cohesive ties. A two-tailed $t$-test for independent groups was used to test for differences between the two age groups. The results of each $t$-test were tested at the .05 level. While all five types of cohesive markers were tracked, only three were used in the statistical analysis for two reasons:

(a) Liles has found inter-judge reliability to be greatest for referential, conjunctive, and lexical markers and (b) multiple t-tests significantly increase the possibility of a Type I error, that is, finding a difference when, in fact, there is none. 
CHAPTER IV

RESULTS AND DISCUSSION

Results

The objective of this study was to gain a greater knowledge of normal language in the healthy elderly. More specifically, the goal was to determine whether there are differences in the use of cohesion in the expository texts of the young-old and the oldest-old. To achieve this information, the research question asked was: When asked to describe a picture, do the cohesive skills (as measured by cohesive frequency, cohesive style, and cohesive adequacy) of the young-old and the oldest-old significantly differ. The ranges, means, and standard deviations of both groups for each of the dependent variables were computed and are shown in Table 4 .

A total of five $t$-tests were performed: (a) one to test for differences in cohesive frequency - the average number of cohesive markers per T-Unit; (b) three to test for differences in cohesive style - the percentage of cohesive markers that were either referential, conjunctive, or lexical; and (c) one to test for differences in cohesive adequacy - determined by the percentage of complete ties. To reduce the number of t-tests and the possibility of a Type I 
Table 4

Descriptive Statistics by Group and Dependent Variable

Measure

Groups

Young-old oldest-old

\begin{tabular}{|c|c|c|c|}
\hline $\begin{array}{l}\text { Cohesive Frequency } \\
\text { (markers/T-Unit) }\end{array}$ & $\begin{array}{l}\text { Mean } \\
\text { SD } \\
\text { Range }\end{array}$ & $\begin{array}{l}1.03 \\
0.540 \\
.42-1.90\end{array}$ & $\begin{array}{l}0.99 \\
0.481 \\
.28-2.71\end{array}$ \\
\hline $\begin{array}{l}\text { Reference } \\
\text { ( } \% \text { of markers that } \\
\text { were references) }\end{array}$ & $\begin{array}{l}\text { Mean } \\
\text { SD } \\
\text { Range }\end{array}$ & $\begin{array}{l}698 \\
20 \\
29-1008\end{array}$ & $\begin{array}{l}728 \\
11.7 \\
46-1008\end{array}$ \\
\hline $\begin{array}{l}\text { Conjunction } \\
\text { ( } 8 \text { of markers that } \\
\text { were conjunctions) }\end{array}$ & $\begin{array}{l}\text { Mean } \\
\text { SD } \\
\text { Range }\end{array}$ & $\begin{array}{l}98 \\
9.1 \\
0-268\end{array}$ & $\begin{array}{l}88 \\
6.2 \\
0-208\end{array}$ \\
\hline $\begin{array}{l}\text { Lexical } \\
\text { ( } \& \text { of markers that } \\
\text { were lexical) }\end{array}$ & $\begin{array}{l}\text { Mean } \\
\text { SD } \\
\text { Range }\end{array}$ & $\begin{array}{l}118 \\
9.9 \\
0-338\end{array}$ & $\begin{array}{l}128 \\
8.9 \\
0-298\end{array}$ \\
\hline $\begin{array}{l}\text { Ellipsis } \\
\text { ( } 8 \text { of markers that } \\
\text { were ellipses) }\end{array}$ & $\begin{array}{l}\text { Mean } \\
\text { SD } \\
\text { Range }\end{array}$ & $\begin{array}{l}48 \\
7.5 \\
0-208\end{array}$ & $\begin{array}{l}38 \\
6.0 \\
0-238\end{array}$ \\
\hline $\begin{array}{l}\text { Substitution } \\
\text { ( } 8 \text { of markers that } \\
\text { were substitutions) }\end{array}$ & $\begin{array}{l}\text { Mean } \\
\text { SD } \\
\text { Range }\end{array}$ & $\begin{array}{l}58 \\
7.3 \\
0-178\end{array}$ & $\begin{array}{l}78 \\
6.4 \\
0-178\end{array}$ \\
\hline $\begin{array}{l}\text { Cohesive Adequacy } \\
\text { ( } 8 \text { complete ties) }\end{array}$ & $\begin{array}{l}\text { Mean } \\
\text { SD } \\
\text { Range }\end{array}$ & $\begin{array}{l}928 \\
10.4 \\
66-1008\end{array}$ & $\begin{array}{l}878 \\
11.9 \\
60-1008\end{array}$ \\
\hline
\end{tabular}


error, t-tests were not computed for the percentage of cohesive markers that were either substitutions or ellipses. Furthermore, those two categories of cohesive markers were used less frequently than the other three. The t-values for each variable (displayed in Table 5) were computed using SYSTAT: The system for Satatistics (Wilkinson, 1987), which had a built-in corrction factor. As predicted, no significant differences were found at the .05 level on any of the measures. A complete list of sample scores is provided in Appendix G.

\section{Discussion}

The results suggest that, given optimal health, cohesive abilities during an expository discourse task are relatively unaffected by age. The failure to find differences between the two groups contradict the theory of inevitable decline. In terms of the decrement with compensation, these results suggest that cohesive abilities remain basically intact with age and may be viewed as relative compensations to any loss of communication skills may occur. Other studies (e.g., Kemper, 1990), have found increases in discourse complexity with declines in cohesive abilities. The apparent contradiction between the results of this study and those studies finding losses in cohesive skills may be due to the optimal health of both groups in this sample. This study examined groups of well-educated people with above-average 
Table 5

t-Values for Each Dependent Variable

\begin{tabular}{cc}
\hline Variable & $\underline{t}$-Value \\
\hline Cohesive Frequency & 0.188 \\
Cohesive style & \\
Reference & 0.638 \\
Conjunction & 0.666 \\
Lexical & 0.346 \\
Cohesive Adequacy & 1.221 \\
\hline
\end{tabular}


vocabulary levels. Given the choice status of the sample and given that people with lower intellectual ability tend to experience more substantial cognitive decline with age (Blum \& Jarvik, 1974, as cited in Howieson et al., 1993), "the extent to which these calculations can be generalized to persons of average and below-average intellectual ability is still unknown" (Howieson et al., 1993, p. 1185). The failure to find differences between the groups, however, may have been affected by some limitations in the study. The samples obtained were rather short and many were simple, slightly elaborated lists of items in the picture. This may be attributed to the instructions given to the subjects and to the type of discourse elicited. The samples may have been richer if the examiner had said, "Describe what is happening in the picture" rather than "Describe the picture." The simple change in instruction encourages the subject to focus on the action of the picture rather than just the object, thereby, providing more about which to talk. Additionally, expository discourse, especially simple picture description, may not be a difficult enough task to find differences, if they exist, among the two groups of elderly. Narrative discourse and conversational discourse may be more appropriate. The extreme difference in group size and the relatively small young-old group also may have attributed to the lack of significant differences, and as a result, the 
t-tests may not have had enough power to detect any differences that might exist. 
CHAPTER V

SUMMARY AND IMPLICATIONS

summary

The purpose of this study was to compare two groups of elderly people's use of cohesion during an expository discourse task. One group was comprised of 12 people between the ages of 65 and 75 years, while the other group consisted of 27 people aged 85 years and older. Each subject was audiotaped while describing the fishing picture from the Neurobehavioral Cognitive Inventory (Kiernan et al., 1987). Each sample was then transcribed, divided into T-Units, and analyzed according to the cohesive analysis designed by Liles (1985) and Liles et al. (1989). Group comparisons for each aspect of cohesion (frequency, style, and adequacy) was completed using a t-test. No significant differences at the .05 level were found on any of the measures.

This study is valuable in that it includes a large sample of optimally-healthy people aged 85 years and older. This population is growing faster than any other in the United States (Neal et al., 1993), and while a considerable amount of research has focused on the language of the elderly (those over 65 years), relatively little study has focused specifically on those aged 85 and older. This sample of 
optimally-healthy oldest-old will help define what changes, if any, are a function of age alone and what changes are clinical (associated with some disease, neurologic complication, or psychological impairment). This delineation could be the basis of future research and could be clinically significant in the treatment of pathologies during the later years.

\section{Implications}

\section{Research}

Implications for further study are far reaching. The possibility of altering the instructions given to the subjects in hopes of encouraging more detail and longer samples has already been addressed in Chapter IV, as has the possibility of performing the same analyses on a different kind of discourse task. Increasing the younger group's size would certainly strengthen any results that may be found. As subjects have been added to the Oregon Brain Aging Study since the original samples were collected, increasing the size of both groups would most likely be a relatively easy task. Other research possibilities could focus on other measures of discourse ability that may be more sensitive to any differences that might exist. These measures might include the following:

1. Comparing the amount of information given in the samples to the amount of information in the stimulus picture 
2. Comparing the number and types of modifiers used by each group

3. Incorporating other measures related to cohesion such as noun-verb ratio, noun-pronoun ratio, and the quality of the identification of characters in the stimulus pictures

4. Investigating how incomplete utterances, false starts, and length of pauses are affected by age. This could be further correlated with the subjects' WAIs vocabulary scores (each subject was given portions of the WAIS as part of the Oregon Brain Aging study).

5. Comparing the groups' performances on a verbal discourse measure with their performances on the visuo-spatial evaluations or the verbal measures (such as vocabulary and verbal reasoning) taken during the oregon Brain Aging study. The visuo-spatial comparison would be particularly interesting since the two groups were found to have the most striking disparity on the visuo-spatial measures .

6. Comparing these two groups' discourse abilities to those of a less than optimally healthy group or groups (e.g., people with aphasia, probable Alzheimer's Disease, or closedhead-injuries. A comparison group comprised of people with possible Alzheimer's Disease could be clinically informative. If a significant difference were found between that group and the oldest-old, the results could be used as a preliminary basis for using an aspect of discourse skills as a 
differential diagnosis for Alzheimer's Disease.

Furthermore, if the ultimate goal is to obtain information on language across the adult life course, then the two groups in this study are not sufficient. Longitudinal data from these same groups would supply a wealth of information to what is already known about the aging process of these particular cohorts. A cross-sectional analysis would also offer an interesting perspective to this study's data. To achieve this goal, a group should be added for every decade from the twenties. This type of study would add to the data base of normal language in adulthood, and particularly, at the later end of the life spectrum.

\section{Clinical}

This new information could help define the evolving views of normal aging both clinically and sociologically. The absence of difference between the groups might help to change common expectations of elderly language, such as the one that the elderly find it difficult to stay on topic (Arbuckle \& Gold, 1993). Perhaps most importantly, results of this study help define the parameters of what is considered to be normal elderly language and what is considered pathological. The group means and standard deviations of each measure of cohesion can serve as preliminary norms. A clinician could use these to assist in the assessment and planning of treatment goals for the elderly with various pathologies. For example, which 
treatment goals are considered appropriate for a 65 year-old stroke patient and which treatment goals are appropriate for an 85 year-old stroke patient may be different, particularly in the area of cohesive adequacy. Although not statistically significant, the difference between the young-old's and oldest-old's mean cohesive adequacy is quite large (92\% complete versus $87 \%$ complete). For a stroke patient whose communication skills are already compromised, using these means as the measure of optimum performance would be a more realistic expectation. Another indicator of disordered language may lie in cohesive style. Both groups in this study had identical hierarchies of cohesive style - using markers of reference most often, followed consecutively by lexical markers, conjunctions, substitutions, and ellipses. since this order is identical and apparently normal, an inordinate amount of ellipses or substitutions could adversely affect cohesive adequacy and indicate a need for intervention. 


\section{REFERENCES}

Arbuckle, T. Y., \& Gold, D. P. (1993). Aging, inhibition, and verbosity. Journal of Gerontology, 48, P225-P232.

Belmore, J.M. (1981). Age-related changes in processing explicit and implicit language. Journal of Gerontology, 36, 316-322.

Bottenberg, D., Lemme, M. L., \& Hedberg, N. (1987). Effect of story content on narrative dscourse of aphasic adults. In R. Brookshire (Ed.), Clinical aphasiology (Vol. 17, pp. 202-208). Minneapolis: BRK Publishers.

Bottenberg, D., \& Lemme, M. L. (1991). Effect of shared and unshared 1 istener knowledge on narratives of normal and aphasic adults. In T. Prescott (Ed.), clinical aphasiology (Vol. 19, pp. 111-116). Austin: Pro-Ed.

Botwinick, J., West, R., \& Sorandt, M. (1975). Qualitative vocabulary response and age. Journal of Gerontology, $30,574-577$.

Boult, C., Kane, R. L., Louis, T. A., Boult, L., \& McCaffrey, D. (1994). Chronic conditions that lead to functional limitation in the elderly. Journal of Gerontology, 49, M28-M36.

Burke, D. M., \& Light, L. L. (1981). Memory and aging: The role of retrieval processes. Psychological Bulletin, 90, 513-546.

Cannito, M. P., Hayashi, M. M., \& Ulatowska, H. K. (1988). Discourse in normal and pathologic aging: Background and assessment strategies. Seminars in speech and Language, 2, 117-134.

Cherney, L. R., \& Canter, G. J. (1990). Informational content and cohesion in the discourse of Alzheimer's Diesease. Paper presented at the 1990 Annual Convention of the American Speech - Language - Hearing Association, Seattle, WA. 
Cherney, L. R., \& Canter, G. J. (1991). Informational content in the discourse of patients with probable Alzheimer's Disease and patients with right brain damage. Paper presented at the Clinical Aphasiology Conference, Destin, FL.

Cohen, G. (1979). Language comprehension in old age. Cognitive Psychology, 11, 412-429.

Craik, F. I. M. (1977). Age differences in human memory. In J. E. Birren \& K. W. Schaie (Eds.), Handbook of the psychology of aging. New York: Van Nostrand Reinhold.

Dixon, R. A., Simon, E. W., Nowack, C. A., \& Hultsch, D. F. (1982). Text recall in adulthood as a function of level of information, input modality, and delay interval. Journal of Gerontology, 37, 358-364.

Halliday, M. A. K., \& Hasan, R. (1976). Cohesion in English. London: Longman.

Halliday, M. A. K., \& Hasan, R. (1986). Lanquage, context, and text: Aspects of lanquage in a social-semiotic perspective. Victoria: Deakin University Press.

Hayslip, B. (1991). Aging: Singular or plural? A psychologist's perspective. Tejas, 17, 35-38.

Hedberg, N. L., \& Stoel-Gammon, C. (1986). Narrative analysis: Clinical procedures. Topics in Lanquage Disorders, I(1), 58-69.

Howieson, D., Kaye, J., \& Howieson, J. (1990). Cognitive status in healthy aging. Unpublished manuscript.

Howieson, D. B., Holm, L. A., Kaye, J. K., Oken, B. S., \& Howieson, J. (1992). Neurologic function in the optimally healthy oldest old: Neuropsychologic evaluation. Neurology, 43, 1882-1886.

Hultsch, D. F., Hammer, M., \& Small, B. J. (1993). Age differences in cognitive performance in later life: Relationships to self-reported health and activity lifestyle. Journal of Gerontology, 48, P1-P1l.

Kaye, J. A., Oken, B. S., Howieson, D. B., Howieson, J., Holm, L., \& Dennison, K. (1992). Neurologic function in the optimally healthy oldest old: Neurologic evaluation. In press. 
Kemper, S. (1990). Adults' diaries: Changes made to written narratives across the life span. Discourse Processes, $13,207-223$.

Kiernan, R. J., Mueller, S., Langston, J. W., \& Van Dyke (1987). Neurocognitive status examination: A brief but differentiated approach to cognitive assessment. Annals of Internal Medicine, 107, 481-485.

Kynette, D., \& Kemper, S. (1986). Aging and loss of grammatical forms. Lanquage and Communication, 6 , 6572 .

Light, L. L., Zelinski, E. M., \& Moore, M. (1982). Adult age differences in reasoning from new information. Journal of Experimental Psychology: Learning, Memory, and Cognition, $8,435-447$.

Liles, B. Z. (1985). Cohesion in the narratives of normal and language-disordered children. Journal of speech and Hearing Research, 28, 123-133.

Liles, B. Z., Coelho, C. A., Duffy, R. J., \& Zalagens, M. R. (1989). Effects of elicitation procedures on the narratives of normal and closed-head injured adults. Journal of Speech and Hearing Disorders, 54, 356-366.

Lovelace, E. A., \& Cooley, S. (1982). Free association of older adults to single words and conceptually related words and triads. Journal of Gerontology, 37, 432-437.

Manney, J. D. (1975). Aging in American society: An examination of concepts and issues. Ann Arbor, MI: The University of Michigan - Wayne State University, Institute of Gerontology, Program for Continuing Education in the Human Services, and School of Social Work.

Mentis, M., \& Prutting, C. A. (1987). Cohesion in the discourse of normal and head-injured adults. Journal of Speech and Hearing Research, 30, 88-98.

Meyer, B. J. F., \& Rice, G. E. (1981). Information recalled from prose by young, middle, and adult readers. Experimental Aging Research, 7, 253-268.

Neal, M.B., Pratt, C.C., \& Schafer, E. (1993). Aging Oregonians: Trends and projections. Portland, OR: Oregon Needs Assessment Steering Committee and Oregon Gerontological Association. 
North, A. J., \& Ulatowska, H. K. (1981). Competence in independently living older adults: Assessment and correlates. Journal of Gerontology, 36, 576-582.

North, A. J., Ulatowska, H. K., Macaluso-Haynes, S., \& Bell, H. (1986). Discourse performance in older adults. International Journal of Aging, 23, 267-283.

Obler, L. K. (1980). Language beyond childhood. In J. Berko-Gleason (Ed.), The development of lanquage. Columbus, OH: Merrill Publishing Company.

Phillips, H. T, \& Gaylord, S. A. (1985). Aging and public health. New York: Springer Publishing Co.

Pratt, M. W., \& Robins, S. I. (1991). That's the way it was: Age differences in the structure and quality of adults' personal narratives. Discourse Processes, 14 , 73- 85 .

Riegel, K. (1968). Changes in psycholoinguist performance with age. In G. Talland (Ed.), Human aging and behavior. New York: Academic Press.

Roth, F., \& Spekman, N. (1989). Higher order language processes and reading disabilities. In Kahmi and Catts (Eds.), Reading disabilities: A developmental language perspective (pp. 159-197). Boston: College-Hill Press.

Schaie, K. W ., \& Gribbin, K. (1975). Adult development and aging. Annual Review of Psychology, 26, 65-96.

Schaie, K. W., \& Hertzog, C. (1983). Fourteen-year cohortsequential analysis of adult intellectual development. Developmental Psychology, 19, 531-543.

Scott, C. M. (1988). Spoken and written syntax. In Nippold (Ed.), Later lanquage development, (pp. 49-46). Austin: Pro-Ed.

Shadden, B.B., Burnette, R.B., Eikenberry, B.R., \& DiBrezzo, R. (1991). All discourse tasks are not created equal.

In T.E. Prescott (Ed.), Clinical aphasiology (Vol. 20)

Austin: Pro-Ed.

Simon, E. W., Dixon, R. A., Nowack, C. A., \& Hultsch, D. F. (1982). Orienting task effects on text recall in adul thood. Journal of Gerontology, 37, 575-580. 
Smith, S. R., Murdoch, B. E., \& Cherney, H. J. (1989). Semantic abilities in dementia of the Alzheimer's type. Brain and Language, 36, 314-324.

strong, C.J. \& Shaver, J.P. (1991). Stability of cohesion in the spoken narratives of language-impaired and normally developing school-aged children. Journal of speech and Hearing Research, 34, 95-111.

Taub, H. A. (1975). Mode of presentation, age, and shortterm memory. Journal of Gerontology, 30, 56-59.

Ulatowska, H. K., North, A. J., \& Macaluso-Haynes, S. (1981). Production of narrative and procedural

discourse in aphasia. Brain and Lanquage, 13, 345-371.

Ulatowska, H. K., Freedman-Stern, Weiss-Doyel, A., \&

Macaluso-Haynes, S. (1983). Production of narrative

discourse in aphasia. Brain and Language, 19, 317-334.

Ulatowska, H. K., Cannito, M. P., Hayashi, M. M. \& Fleming, S. G. (1985). Language abilities in the elderly. In H. K. Ulatowska (Ed.), The aging brain: Communication in the elderly. San Diego: College Hill Press.

Ulatoska, H. K., \& Chapman, S. B. (1989). Discourse considerations for aphasia management. Seminars in Speech and Language, 10, 298-314.

Warren, D. K. Bayles, K. A., \& Trosset, M. W. (1991). Lonaitudinal effects of Alzheimer's disease on discourse production in three patients. Unpublished manuscript.

Wilkinson, L. (1987). SYSTAT: The system for statistics. Evanston, IL: SYSTAT, InC. 
APPENDIX A

COHESION AND COHESIVE MARKERS 


\section{COHESION AND COHESIVE MARKERS}

1) Reference: the cohesive marker specifically refers to an item that can be directly retrieved within the text.

Examples: John had a birthday. He was 32 .

Sue's office is her castle. You can always find her there.

In the first example the pronoun "he" directly refers to John. Likewise in the second example, "there" refers specifically to sue's office. In both cases, the cohesive markers refer to an item whose precise meaning can be retrieved.

2) Substitution: the cohesive marker is substituted for the item to which it refers. When cohesive markers are used as substitution, they are not used as an exact replacement for the referent.

Examples: My shirt is dirty. I'll put on a clean one.

I've finished my cookie. May I please have another.

In the first example, "one" is substituted for "shirt," but not the exact "shirt" described in the first sentence.

Similarly, "another" is substituted for the original cookie. Acting as substitutes, these cohesive markers are not exact representations of the referent.

3) Ellipsis: are ties where the actual cohesive element is left unsaid, but rather is presupposed based on information given in the first half of the tie.

Examples: I told them to go home. But they didn't. Which coat is yours? The red.

In both instances, the second sentence does not actually contain a cohesive marker, but the referent can be presupposed by the given information.

4) Conjunction: involves the use of conjunctions to link the ties. The conjunction used will determine the exact relationship. For example, the conjunction "and" creates an additive quality; whereas the conjunction "but," suggests an adversative quality. 
Examples: I can never remember exact dates. Otherwise, I would have sent you a birthday card.

she picked up the phone, but she did not speak.

5) Lexical: cohesion is created because of the selected vocabulary. The cohesive element is somehow related to the referent, whether it be a direct repetition, a synonym, or a member of the same semantic class.

Examples: I like carrots. In fact, I like most vegetables.

We went to visit our cousins. They are the nicest relatives we have.

We chose the white cat. She was the prettiest animal we had ever seen. 
APPENDIX B

BATTERY OF NEUROLOGICAL AND NEUROPSYCHOLOGICAL EVALUATIONS OF HOWIESON ET AL. (1993) AND KAYE ET AL. (1994) 
BATTERY OF NEUROLOGICAL AND NEUROPSYCHOLOGICAL EVALUATIONS HOWIESON ET AL. (1993) AND

KAYE ET AL. (1994)

\section{Neurological Assessments}

1. An examination of vital signs and cranial nerve functioning

2. An assessment of the primary motor systems

3. An evaluation of the motor systems

\section{Neuropsychological Assessments}

1. The Neurobehavioral Cognitive status Examination (Kiernan et al., 1987)

2. The Temporal Orientations Test

(Benton, Van Allen, \& Fogel, 1964)

3. The picture completion test from the Wechsler Adult Intelligence Test - Revised (WAIS-R)

(Wechsler, 1981)

4. The block design test from the WAIS-R

(Wechsler, 1981)

5. Two tests of digit span from the Wechsler Adult Intelligence scale (WAIS)

(Wechsler, 1955)

6. The Logical Memory I and Logical Memory II portions of the Wechsler Memory Scale - Revised (WMS-R)

(Wechsler, 1987)

7. The Visual Reproduction I and Visual Reproduction II portions of the WMS-R

8. The word list task from the Consortium to Establish a Registry for Alzheimer's Disease (CERAD) battery (Morris et al., 1989)

9. The Boston Naming Test

(Goodglass \& Kaplan, 1983)

10. The verbal reasoning subtest of the Cognitive Competency Test

(Wang \& Ennis, 1986) 
APPENDIX C

ADVERTISEMENT SEEKING VOLUNTEERS 


\section{RESEARCH \\ VOLUNTEERS NEEDED}

The Oregon Brain Aging Study is recruiting subjects for a five year study. The purpose of the study is to learn about cognitive changes (memory, concentration, problem solving) in healthy individuals, 65 years of age and older.

Researchers Drs. Jeffrey Kaye and Diane Howieson hope to better understand normal changes in brain structure and mental functioning in healthy older adults. The data collected will be used to make comparisons with the cognitive functioning and brain structure changes of Alzheimer's patients. This information may help in the diagnosis, prevention and treatment of Alzheimer's disease in the future.

As part of the study our volunteers come in annually for two or three morning visits. We provide:

- Physical examination, blood test screen (sugar, cholesterol), chest $x$-ray and EKG.

- Neuropsychological exam, testing the volumteer's concentration, memory and problem solving skills.

- Magnetic Resonance Imaging (MRI) scan picture of the brain.

- Transportation is provided for those who do not drive.

THE NEED FOR THIS WOAK:

- Approximately 4 million Americans are affected by Alzheimer's disease.

- It has been estimated that more than 100,000 Americans die of Alzheimer's disease annually, making it the fourth leading cause of death in adults, after heart disease, cancer and stroke.

- Currently there is little research data available about the effects of healthy aging on the brain.

The study is currently enrolling men over 65 years of age and women over 85 years of age.

If you are interested in participating, and are not on medication for heart disease, high blood pressure or diabetes, please call Suzanne at 494-7616.

The Orgon Brain Aging Study is a ipint project of the Deparment of Voterans Aftairs. Oregon Health Sciancess Universay, the Alzheimer's Disease Conter and the Alzhewners Diseses Conter of Oregon. 


\section{APPENDIX D}

\section{FISHING PICTURE}

Source: Kiernan, R. J., Mueller, S., Langston, J. W. \& Van Dyke, C. (1987). Neurocognitive status examination: A brief but differentiated approach to cognitive assesment. Annals of Internal Medicine, 107, 481-485. 


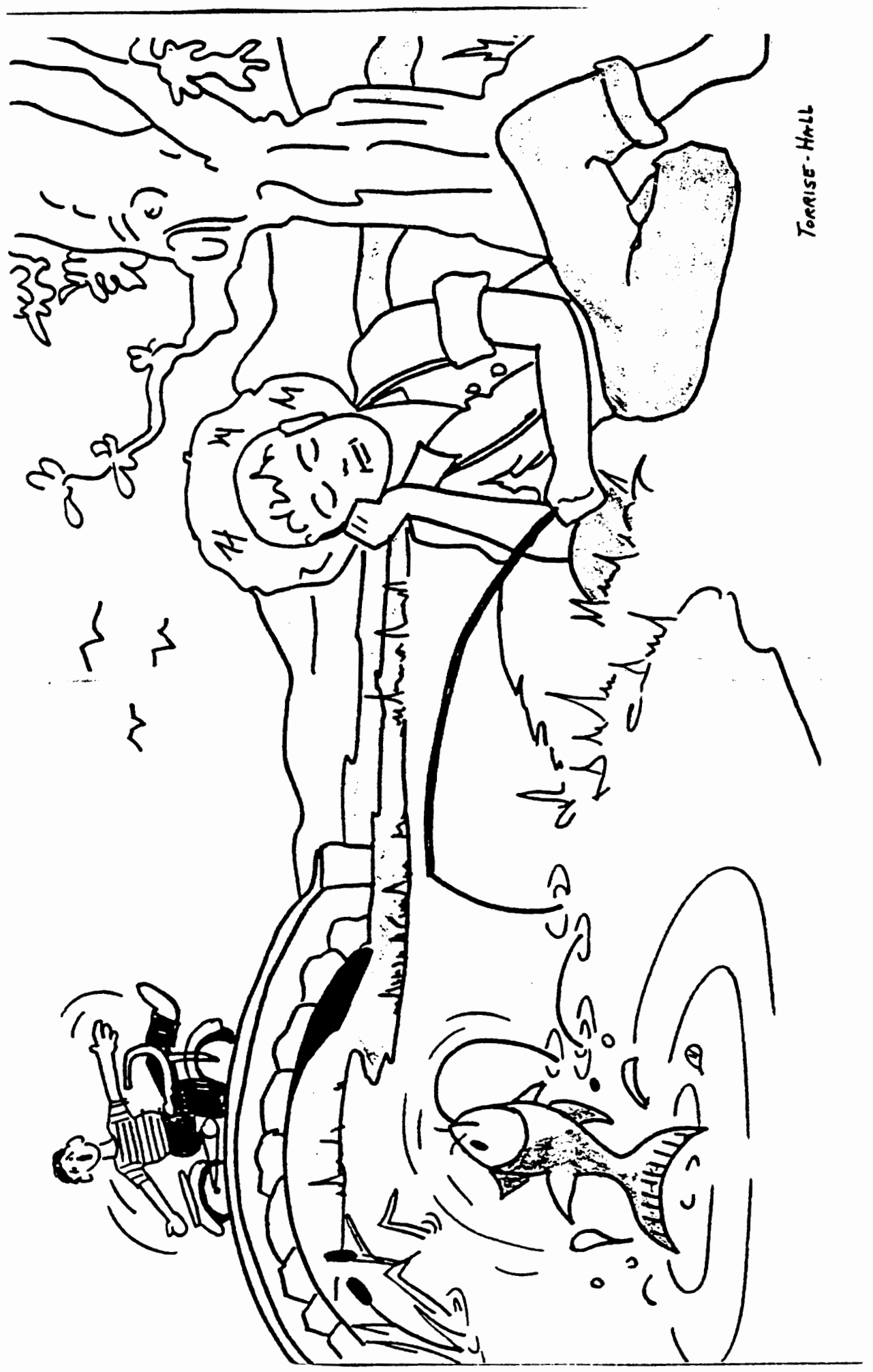




\section{APPENDIX E}

PROCEDURES FOR T-UNIT TRANSCRIPTION 
PROCEDURES FOR T-UNIT TRANSCRIPTION

The following rules adapted from strong and Shaver (1991) were used for dividing the samples into T-Units.

Basic Rules to Follow when Transcribing:

1. Exact repetitions of words or syntactic and/or semantic revisions are placed in parentheses ( ).

2. Syntactic and/or semantic revisions that did not have a complete thought were not counted.

3. T-Units were counted even if not grammatically correct.

4. Quotation marks are used to signify direct quotations. Direct quotations that complete a verb phrase are not considered as a separate T-Unit (e.g. He looked at the dog and said, "That's my frog."). If direct quotations include more than one sentence, apply the segmentation rules and identify separate T-Units (e.g. The kid's goin crazy because he thinks, "The darn fool." [T] "She's sound as leep."

5. Sentence fragments wre counted when utterance final intonation countours clearly indicated that a complete thought had been spoken.

6. New T-Units that were a continuation of an utterance were coded with a [T] before the first word of the new T-Unit.

\section{Example of T-Unit Transcription}

1. She's tryin to fish I suppose.

2. [T] But she's pretty lazy about it.

3. But she's got one on her hook,

4. [T] And she doesn't know it.

5. This kid's goin crazy because he thinks, "The darn fool."

6. [T] "She's sound asleep."

7. [T] "You got a fish."

8. [T] "You better get it up and get it out if that's your business." 


\section{APPENDIX F}

PROCEDURES FOR COHESIVE ANALYSIS

Source: Liles, B. Z. (1985). Narrative ability in normal ans language disordered children. Journal of speech and Hearing Research, 28, 123-133. 
PROCEDURES FOR THE IDENTIFICATION OF COHESIVE MARKERS

In this procedure it is important that the examiner be familiar with the stimulus to which the sample efers. First read the entire narrative to get an overall sense of the text. Then read each sentence separately as a complete unit before identifying those items in the sentence that mark cohesion.

At this stage in the procedure the examiner views each sentence as isolated from the text. From this viewpoint the examiner judges an item to be a cohesive element or not under the following conditions:

1. Definition of a cohesive marker. An element is identified as a cohesive marker if its meaning cannot be adequately interpreted by the listener and if the listener must "search" outside that sentence for the completed meaning.

In addition, an element may be judged a cohesive element if it is used as a linguistic marker that leads the listener to "expect" that its interpretation is outside the sentence (e.g., definite articles).

Cohesive markers may be reference, conjunction, lexical, substitution, or elliptical.

2. Relationships within the sentence, Do not judge an item as a cohesive marker if the information referred to is recoverable within the sentence. The following are examples of information recovered within the sentence.

Some boys took theif car home.

Personal reference their refers to boys; therefore, the information is recoverable within the sentence.

There was this scientist that had a hideout in these mountains where there was this radar tower to blow up metal things that fly in the air.

In the example above the information referred to by the use of this and these as selective demonstrative references (Halliday \& Hasan, 1976 p. 70) is recovered within the sentence. Thus, the examiner would not identify this or these as a cohesive marker (i.e., information recoverable outside the sentence). 
The next example demonstrates a cohesive and a noncohesive marker in the same sentence.

One of the boys went home.

The demonstrative reference the marks which or what boys, and serves as a cue to the listener that the information is recoverable outside the sentence and is, therefore, cohesive. However, one refers within the sentence to boys and is not a cohesive marker.

3. Text influence on judgment. Although this procedure calls for the examiner to view each sentence as independent from the text when identifying cohesive markers, there are instances when the text must be considered. For example, in the sentence,

Marie didn't want to go on the hike.

the listener may need more information about Marie in order to comprehend the text. In this particular text, the listener would ask, "Who is Marie?"

Thus the decision as to whether a particular item is a cohesive marker or not is "text dependent." As texts vary specific items may vary in their cohesive function.

(a) Text influence on demonstrative reference. While the is a selective demonstrative reference, it may also be used in combination with words to express a unit of meaning (e.g., "the road," "the radio," "the newspaper"). It may be difficult to

determine when the speaker intends the as a selective demonstrative reference or if the is used as an uninflected functor. To make this judgment, the examiner must take the text into consideration. For example, if the speaker used "the road" and the examiner judges that reference to a particular road is important within the text, he/she may judge that the speaker intended the to be used as a selective reference and would identify it as a cohesive marker. The following rule will facilitate judgment:

If in doubt about the use of "the" because of the above reasons, do not code the as a selective demonstrative reference if a or some can be substituted without producing a crucial change in the meaning of the text.

4. Two or more cohesive markers within a sentence.

(a) Conjunctions. When two or more conjunctions (e.g., and then or and so then) are conjoined in 
a sentence, code only one of the conjunctions as a cohesive item. Select the conjunction that is the most complex according to the following hierarchy:

(a) Causal, (b) Adversitive, (c) Temporal,

(d) Additive.

(b) Reference: Demonstrative and comparative. When both a demonstrative and comparative reference are used (e.g., the other code only as one cohesive item (comparative) rather than as two items (demonstrative and comparative).

(c) Reference: Personal and demonstrative. If two or more references (i.e., either personal or demonstrative) are judged to be cohesive in the same sentence, code all markers even though they refer to a common reference. For example,

He took his comic books home.

Although the sentence structure indicated that his refers within the sentence to he, there is no lexical support within the sentence to provide the listener with the information needed to know to whom his refers. Therefore, he and his are both cohesive.

After the examiner has identified the cohesive markers within each sentence according to the procedure presented above, he/she should then reread the sentence with a different perspective. The markers that had been identified as cohesive are now viewed as part of the text.

Since each cohesive marker must (or should) be ties to information recoverable elsewhere in the text, the examiner locates the sentence containing the tied information. The sentence number and item are noted.

\section{PROCEDURE FOR THE IDENTIFICATION OF COHESIVE ADEQUACY}

1. Complete tie. A tie is complete if the information referred to by the cohesive marker is easily found and defined with no ambiguity.

2. Incomplete tie. A tie is judged to be incomplete if:

(a) The information referred to by the cohesive marker is not provided in the text. For example, 
Two boys went to see a movie.

They saw his car parked in front.

In this example, the speaker had not provided the information (i.e., whose car?) but used the personal reference his, cueing the listener to recover information outside the sentence.

(b) The listener is guided to ambiguous information. For example,

Homer and Freddie went to the movie.

He enjoyed it very much.

In this case, the listener would not know which boy enjoyed the movie.

3) Conjunctions are a special case of erroneous tying. Since one cannot judge reliably an inappropriate use of conjunction as incomplete, all conjunctions that are not completely adequate are judged to be errors.

Accordingly, if the ideas or messages presented in the two conjoined sentences are unrelated or inappropriately sequenced, the conjunction used to join the ideas are judged to be errors.

The follwoing two pages include a coded language sample and a completed worksheet used for scoring the sample. 
DISCOURSE SAMPLE

1. A boy's sleeping under a tree

2. He has a fish on ...

3. He sould be waking up to get the fish

4. And there's a boy on a bicycle not using the handlebars as he goes across the bridge

5. There's some cattails in the picture

6. A few leaves on the tree

7. Three birds in the sky

8. Okay, he has on a straw hat

9. It makes you think a little bit of Huckleberry Finn

10. Torrise Hall apparently drew the picture

11. And there's some grass growing (along the) by the tree and along the bank of the river 
COHESION WORKSHEET

Cohesive Marker Tied to info Type of

Judgement Line\#/Item Line \#/Item cohesion

$\begin{array}{lccc}2 / \text { he } & 1 / \text { boy } & \text { reference } & \mathrm{x} \\ 2 / \text { on } . . & 1 / \text { ellipsis } & \\ 3 / \text { he } & 1 / \text { boy } & \text { reference } & \mathrm{x} \\ 3 / \text { waking } & 1 / \text { sleeping lexical } & \mathrm{x} \\ 3 / \text { the } & 2 / \text { fish } & \text { reference } & \mathrm{x} \\ 6 / \text { the } & 1 / \text { tree } & \text { reference } & \mathrm{x} \\ 8 / \text { he } & \text { ? } & \text { reference } & \\ 9 / \text { it } & 8 / \text { hat } & \text { reference } & \mathrm{x} \\ 11 / \text { the } & 1 / \text { tree } & \text { reference } & \mathrm{x}\end{array}$

Total \# of markers:

Total \# of ties:

Reference: $\quad 7 / 9=77 \%$

* Complete: $7 / 9=778$

\& substitution:

0

8 Incomplete/

\& Conjunction:

0

Ambiguous:

$2 \angle 9=228$

Cohesive

Ellipsis: $1 / 9=118$

frequency: $9 / 11=.82$

\& Lexical: $1 / 9=118$ 
APPENDIX G

SAMPLE SCORES 
SUMMARY OF SAMPLE SCORES

YOUNG-OLD

\begin{tabular}{|c|c|c|c|c|c|c|c|}
\hline Sample & Freq. & Ref. & Conj. & Lex. & sub. & Ellip. & Adeq \\
\hline 1 & .60 & 668 & 08 & 228 & 118 & $0 \%$ & $66 \%$ \\
\hline 2 & 1.59 & $28 \%$ & $25 \%$ & $8 \%$ & $17 \%$ & $20 \%$ & 978 \\
\hline 3 & 1.00 & 508 & $20 \%$ & 208 & $5 \%$ & 58 & 958 \\
\hline 4 & 1.53 & $70 \%$ & $17 \%$ & 138 & $0 \%$ & 08 & 1008 \\
\hline 5 & 1.90 & $70 \%$ & 178 & $8 \%$ & 28 & 28 & $78 \%$ \\
\hline 6 & .50 & $50 \%$ & 08 & $0 \%$ & $20 \%$ & 208 & $100 \%$ \\
\hline 7 & 1.06 & $88 \%$ & 68 & $6 \%$ & $0 \%$ & $0 \%$ & 888 \\
\hline 8 & .88 & $80 \%$ & 68 & 138 & $0 \%$ & $0 \%$ & $93 \%$ \\
\hline 9 & .60 & $80 \%$ & 138 & $8 \%$ & $0 \%$ & $0 \%$ & 868 \\
\hline 10 & .50 & $100 \%$ & 08 & $0 \%$ & 08 & $0 \%$ & 1008 \\
\hline 11 & .42 & $66 \%$ & $0 \%$ & 338 & 08 & $0 \%$ & 1008 \\
\hline 12 & 1.78 & $81 \%$ & $5 \%$ & 28 & $8 \%$ & 28 & $94 \%$ \\
\hline
\end{tabular}

Sample Freq. Ref. Conj. Lex. Sub. Ellip. Adeq.

$\begin{array}{rrrrrrrr}1 & 1.52 & 78 \% & 12 \% & 6 \% & 3 \% & 0 \% & 88 \% \\ 2 & .60 & 100 \% & 0 \% & 0 \% & 0 \% & 0 \% & 100 \% \\ 3 & .50 & 75 \% & 0 \% & 258 & 0 \% & 0 \% & 100 \% \\ 4 & .64 & 71 \% & 0 \% & 28 \% & 0 \% & 0 \% & 85 \% \\ 5 & 1.22 & 64 \% & 0 \% & 27 \% & 98 & 0 \% & 648\end{array}$


OLDEST-OLD (continued)

\begin{tabular}{|c|c|c|c|c|c|c|c|}
\hline Sample & Ereq. & Ref. & Conj. & Lex. & sub. & Ellip. & Adeq. \\
\hline 6 & 1.05 & 628 & 108 & 198 & 98 & $0 \%$ & $90 \%$ \\
\hline 7 & 1.43 & 628 & $14 \%$ & 28 & $11 \%$ & 68 & 848 \\
\hline 8 & .83 & 808 & $0 \%$ & 108 & $0 \%$ & 108 & $80 \%$ \\
\hline 9 & .69 & $78 \%$ & $11 \%$ & $11 \%$ & 08 & $0 \%$ & 888 \\
\hline 10 & 1.00 & 468 & $8 \%$ & $8 \%$ & $15 \%$ & 238 & 928 \\
\hline 11 & .45 & $60 \%$ & 208 & $20 \%$ & 08 & $0 \%$ & $80 \%$ \\
\hline 12 & 1.14 & 818 & 68 & 68 & 08 & 08 & 948 \\
\hline 13 & 1.06 & 768 & $12 \%$ & $12 \%$ & 08 & $0 \%$ & 948 \\
\hline 14 & .66 & $83 \%$ & $0 \%$ & 08 & 08 & 168 & 668 \\
\hline 15 & 1.06 & 838 & 58 & $0 \%$ & 118 & $0 \%$ & $78 \%$ \\
\hline 16 & 1.13 & $70 \%$ & 58 & $18 \%$ & $5 \%$ & $0 \%$ & $82 \%$ \\
\hline 17 & .28 & $100 \%$ & 08 & $0 \%$ & $0 \%$ & 08 & $100 \%$ \\
\hline 18 & 1.40 & $66 \%$ & $14 \%$ & 148 & $0 \%$ & 48 & 958 \\
\hline 19 & 1.39 & 688 & $8 \%$ & 188 & $6 \%$ & 08 & $82 \%$ \\
\hline 20 & 1.00 & $80 \%$ & 108 & $10 \%$ & 08 & 08 & $65 \%$ \\
\hline 21 & 1.25 & $60 \%$ & 208 & 208 & $0 \%$ & 08 & $100 \%$ \\
\hline 22 & 1.16 & $64 \%$ & 148 & 78 & $7 \%$ & 78 & $92 \%$ \\
\hline 23 & .50 & 668 & $0 \%$ & $16 \%$ & $16 \%$ & $0 \%$ & $83 \%$ \\
\hline 24 & 1.00 & $70 \%$ & $10 \%$ & 108 & 08 & 08 & 608 \\
\hline 25 & .69 & 668 & 118 & $22 \%$ & $0 \%$ & 08 & 1008 \\
\hline 26 & 2.71 & 748 & $52 \%$ & $21 \%$ & $0 \%$ & $0 \%$ & 948 \\
\hline 27 & .57 & 668 & 08 & $0 \%$ & 228 & $11 \%$ & 1008 \\
\hline
\end{tabular}

